\title{
The effect of giving potty training on the skills of defecating and urinating at toddler
}

\author{
Yosefina Nelista $^{1}$, Pembronia Nona Fembi ${ }^{1}$, Teresia Elfi $^{1}$
}

1 Program Studi S1 Keperawatan, Fakultas Ilmu-Ilmu Kesehatan, Universitas Nusa Nipa, Indonesia

\begin{tabular}{|c|c|}
\hline Article Info & Abstract \\
\hline $\begin{array}{l}\text { Article History: } \\
\text { Submitted: May 24th }, 2021 \\
\text { Accepted: Oct 19th }, 2021 \\
\text { Published: Nov } 25^{\text {th }}, 2021 \\
\text { Keywords: } \\
\text { potty training, skills, } \\
\text { defecation and urination }\end{array}$ & $\begin{array}{l}\text { Toddlers are an effective age to develop their various potentials which } \\
\text { include physical, motor, cognitive, social-emotional development and } \\
\text { language development. One of the child's developmental tasks is toileting } \\
\text { skills or what are known as urinating and defecating skills. A skill that should } \\
\text { be introduced early in toddlers to prevent enuresis is potty training. This } \\
\text { study aims to analyze the effect of giving potty training on the independence } \\
\text { of defecation and urination in toddlers. The type of research used is Quasy } \\
\text { Experiment with one group pretest-posttest design research design. This } \\
\text { study design only conducted an intervention in one group, without } \\
\text { comparison. The population in this study were all children under five as } \\
\text { many as } 85 \text { people. The sampling technique used purposive sampling so that } \\
\text { the sample size in this study amounted to } 30 \text { people. Data analysis using } \\
\text { Paired Samples Test. The results showed that there where there is an effect } \\
\text { of giving potty training on defecation and urination skills in toddlers (p- } \\
\text { value } 0.000<\alpha 0.05 \text { ). So it can be concluded that giving Potty Training can } \\
\text { improve defecation and urination skills in toddlers. }\end{array}$ \\
\hline
\end{tabular}

\section{PENDAHULUAN}

Toddler atau anak usia batita adalah usia yang efektif untuk mengembangkan berbagai potensi anak meliputi perkembangan fisik, motorik, kognitif, perkembangan emosional dan perkembangan bahasa [1]. Salah satu tugas perkembangan anak pada usia ini adalah keterampilan toileting atau yang disebut keterampilan buang air kecil dan buang air besar. Keterampilan toileting terdiri dari keterampilan mengontrol buang air kecil (bladder control) dan mengontrol buang air besar (bowel control). Toilet training membantu mengembangkan keterampilan buang air kecil dan buang air besar pada anak [2]. Toilet training merupakan bagian dari perkembangan batita karena dapat meningkatkan kepercayaan diri dan kemandirian anak [3]. Rata-rata usia toilet training anak adalah 24-36 bulan dan keterampilan ini tercapai pada fase batita [4].

Keterampilan buang air kecil dan buang air besar yang gagal diperoleh dalam rentang waktu toilet training dapat menimbulkan masalah berupa dysfunctional voiding berupa enuresis, infeksi saluran kencing, sembelit, enkopresis dan penolakan untuk pergi ke toilet [4,5]. Kegagalan toilet

Corresponding author:

Yosefina Nelista

nelistayosefina@gmail.com

Media Keperawatan Indonesia, Vol 4 No 4, November 2021

e-ISSN: 2615-1669

ISSN: 2722-2802

DOI: $10.26714 /$ mki.4.4.2021.270-276 
training yang berlanjut seperti nocturnal bladder control akan berdampak pada masalah neuropsikiatri dan perilaku bunuh diri [6].

Prevalensi enuresis di dunia berkisar antara 11.4\%-45\%. Penelitian di USA menunjukkan dari dari 112 anak usia 3-10 tahun, $45 \%$ di antaranya mengalami daytime wetting atau mengompol di siang hari. Di Qena, Mesir, sebanyak 1065 (11.4\%) anak usia sekolah mengalami enuresis [7]. Afrika Selatan, sebanyak 16\% dari 4700 anak usia 5-10 mengalami nocturnal enuresis. Di Baghdad, dari 610 anak ditemukan 127 (20.8\%) mengalami enuresis [8,9].

Berdasarkan studi pendahuluan di wilayah kerja puskesmas Waipare, jumlah anak usia BATITA sebanyak 85 anak. Informasi dari kader Posyandu menyatakan bahwa banyak anak yang kurang memiliki keterampilan buang air kecil dan buang air besar dan masih menggunakan diapers. Sering dijumpai anak yang masih mengompol saat kegiatan posyandu berlangsung. Para orang tua dan pengasuh berupaya melatih anak dengan melepas diapers dan mengajak anak untuk buang air kecil dan buang air besar di toilet, belum ada metode khusus yang diterapkan untuk melatih keterampilan buang air kecil dan buang air besar anak. Salah satu ketrampilan penting yang dikenalkan sejak dini pada anak usia batita untuk mencegah enusresis adalah potty training.

Potty training merupakan proses membiasakan anak untuk berpindah dari menggunakan popok dan saatnya kemudian menggunakan toilet. Potty training sebaiknya dilakukan sejak dini. Idealnya potty training diberikan setelah anak memasuki usia 18 bulan, karena pada usia tersebut anak telah mampu berdiri sendiri dengan baik, duduk dan jadwal BAB yang semakin teratur [10].

Berdasarkan studi pendahuluan, peneliti tertarik untuk melakukan penelitian tentang pengaruh potty training terhadap keterampilan buang air kecil dan buang air besar pada anak usia batita. Tujuan dari penelitian adalah menganalisis pengaruh pemberian potty training terhadap Ketrampilan Buang Air Besar dan Buang Air Kecil Pada Anak Usia BATITA.

\section{METODE}

Jenis penelitian yang digunakan yaitu quasy experiment dengan desain one group pretest posttest design. Desain penelitian ini hanya melakukan intervensi pada satu kelompok, tanpa pembanding. Populasi dalam penelitian ini semua anak usia batita sebanyak 85 orang. Teknik pengambilan sampel menggunakan purposive sampling, sehingga besar sampel dalam penelitian ini berjumlah 30 orang.

Kriteria Inklusi dalam penelitian ini: 1) Batita dengan usia 24-36 bulan, 2) Batita yang bisa mengikuti dan mengerti perintah, 3) Batita yang dapat berjalan dan duduk dengan tidak goyah, 4) Batita yang mampu mengenakan dan melepas celana sendiri. Kriteria Eksklusi dalam penelitian ini adalah 1) Batita yang tidak kooperatif, 2) Batita yang disabilitas, 3) Batita yang sakit.

Instrumen yang digunakan dalam penelitian ini adalah toileting skill. Instrument ini digunakan untuk mengukur keterampilan buang air kecil dan buang air besar yang diadopsi dari toilet skilss assesment yang telah terpublikasi dan guideline toilet training dari American Academy of Pediatric 2004. Toilet skills assesment disusun oleh royal college of nursing di London pada tahun 2013 dan dilakukan peer review oleh tim ahli, diantaranya Association for Continence Advice (ACA) Executive Committee; PromoCon, Disabled Living, Manchester; RCN Continence. Instrumen ini terdiri dari komponen keterampilan bladder dan bowel, kemandirian, serta keterampilan yanglain. Uji validitas kuesioner dilakukan melalui 2 tahapan yaitu face validity dan uji coba kuesioner. Face validity dilakukan dengan 
mengonsultasikan kuesioner kepada perawat anak. Uji coba kuesioner dianalisis menggunakan correlation product moment dengan nilai signifikansi $5 \% \quad(n=12, r$ tabel=0.5760). Uji reliabilitas instrumen dalam penelitian menggunakan alpha chronbach [11]. Penelitian dilaksanakan setelah mendapatkan uji kelayakan Etik dari Komisi Etik Penelitian Kesehatan (KEPK) Fakultas kedokteran Universitas Nusa Cendana.

Pengumpulan data meliputi: 1) Pretest. Sebelum diberikan intervensi potty training, dilakukan pengukuran ketrampilan buang air besar dan buang air kecil pada batita dalam bentuk kuesioner. 2) Intervensi. Intervensi yang diberikan adalah potty training pada batita diberikan selama tiga kali dalam seminggu selama satu bulan dengan durasi waktu 15-30 menit. 3) Posttest. Setelah diberikan intervensi potty training selama satu bulan, dilakukan pengukuran ketrampilan buang air besar dan buang air kecil dalam bentuk kuesioner. Pengolahan data pada penelitian ini meliputi editing, coding, processing, cleaning dan tabulating. Analisis data menggunakan uji Paired Samples T-Test.

\section{HASIL}

Karakteristik usia anak paling banyak berusia 31-36 bulan yang berjumlah 20 anak (66.7\%), lebih banyak anak berjenis kelamin perempuan berjumlah 22 anak (73.3\%). Penggunaan diapers, paling banyak menggunakan diapers pada saat kondisi tertentu yaitu sebanyak 11 anak (36.7\%). Karakteristik responden dari penelitian ini tertera pada tabel 1 .

Karakteristik Pendidikan orang tua paling banyak berpendidikan SMA yaitu sebanyak 14 orang (46.7\%) dan karakteristik Pekerjaan orang tua paling banyak mempunyai pekerjaan sebagai Ibu Rumah Tangga yaitu sebanyak 14 orang (46.7\%). Nilai mean pretest untuk kemampuan BAB dan BAK sebesar 49.23, sedangkan nilai mean posttest untuk kemampuan BAB dan
BAK sebesar 62.40, karena nilai mean pretest < nilai mean posttest $(49.23<62.40)$ maka dapat diartikan bahwa ada perbedaan kemampuan $\mathrm{BAB}$ dan BAK sebelum dan setelah diberikan potty training.

Tabel 3 di atas menunjukkan nilai t hitung > $\mathrm{t}$ tabel $(14.848>2.0452)$ dan nilai $\mathrm{p}$ value $0.000(0.000<0.05)$ maka Ha di terima, yang artinya ada Pengaruh Pemberian Potty Training Terhadap Keterampilan Buang Air Besar dan Buang Air Kecil Pada Anak Usia BATITA.

Tabel 1

Karakteristik responden $(\mathrm{n}=30)$

\begin{tabular}{lcc}
\hline \multicolumn{1}{c}{ Indikator } & $\mathrm{f}$ & $\%$ \\
\hline Pendidikan & & \\
SD & 4 & 13.3 \\
SMP & 5 & 16.7 \\
SMA & 14 & 46.7 \\
PT & 7 & 23.3 \\
\hline Pekerjaan & & \\
Ibu Rumah Tangga & 14 & 46.7 \\
Penjahit & 2 & 6.7 \\
Karyawan swasta & 2 & 6.7 \\
Guru & 4 & 13.3 \\
Wiraswasta & 5 & 16.7 \\
PNS & 3 & 10.0 \\
\hline
\end{tabular}

Tabel 2

\begin{tabular}{lcc}
\multicolumn{3}{c}{ Orang tua responden $(\mathrm{n}=30)$} \\
\hline Variabel & $\mathrm{f}$ & $\%$ \\
\hline Usia (bulan) & & \\
24-30 bulan & 10 & 33.3 \\
31-36 bulan & 20 & 66.7 \\
\hline Jenis Kelamin & & \\
$\quad$ Laki-laki & 8 & 26.7 \\
$\quad$ Perempuan & 22 & 73.3 \\
& & \\
\hline Penggunaan Diapers & & \\
$\quad$ Tidak menggunakan & 10 & 33.3 \\
Hanya malam hari saat tidur & 6 & 20.0 \\
$\quad$ Saat kondisi tertentu & 11 & 36.7 \\
Sepanjang hari & 3 & 10.0 \\
\hline
\end{tabular}


Tabel 3

Pengaruh Pemberian Potty Training terhadap Keterampilanbuang air besar dan buang air kecil $\frac{\text { pada anak usia BATITA }(\mathrm{n}=30)}{\text { Indikator }}$

Kemampuan BAB dan BAK sebelum perlakuan

$49.23 \pm 4.34$

\begin{tabular}{cc}
\hline $\begin{array}{l}\text { Kemampuan BAB dan BAK } \\
\text { setelah perlakuan }\end{array}$ & $62.40 \pm 3.10$ \\
\hline $\mathrm{p}$ & 0.0001 \\
\hline
\end{tabular}

*Paired samples $t$ test

\section{PEMBAHASAN}

Penelitian ini menunjukkan bahwa ada peningkatan kemampuan buang air besar dan buang air kecil sebelum dan setelah diberikan potty training. Toilet training menggunakan potty dikatakan berhasil apabila anak memberitahu orang tua apabila merasa ingin buang air kecil (BAK) atau buang air besar (BAB), mampu menahan buang air kecil atau buang air besar, mampu membersihkan atau cebok dengan sendiri serta anak tidak pernah ngompol atau buang air besar di celana. Toilet training dikatakan terlambat apabila anak terlambat memberitahu bila merasa buang air kecil atau buang air besar, terlambat mengatakan pada ibu bila buang air kecil atau buang air besar dan anak mengompol atau buang air besar di celana tanpa disadari [12].

Keterampilan BAB dan BAK merupakan salah satu tugas perkembangan anak yang dimulai pada usia 2,5sampai 3 tahun [13]. Mengajarkan keterampilan buang air kecil dan buang air besar pada anak usia 24-36 bulan adalah bagian dari stimulasi agar dapat meningkatkan sosialisasi dan kemandirian batita [14]. Berdasarkan konsep perkembangan anak, kontrol sfingter yang terdiri dari bowel control dan bladder control adalah bagian dari tugas perkembangan personal pada aspek kebiasaan (habit) [15].

Pemberian potty training pada batita merupakan teknik untuk melatih batita agar buang air kecil maupun buang air besar di kamar mandi secara mandiri. Pemilihan intervensi pemberian potty pada penelitian ini karena berdasarkan observasi, anak cenderung takut untuk latihan langsung di toilet seperti orang dewasa. Anak seringkali menolak untuk duduk di toilet karena takut jatuh dan takut akan lubang toilet. Oleh karena itu, peneliti menggunakan potty untuk melatih keterampilan BAB dan BAK pada batita. Potty yang digunakan pada penelitian ini sesuai dengan usia anak dan diletakkan di atas lantai sehingga lebih rileks dan tidak merasa takut.

Pemberian potty training pada penelitian ini dilakukan pada anak usia 24-36 bulan. Hal ini sejalan dengan pendapat dari Hodges yang menyatakan bahwa usia yang tepat untuk dilakukan toilet training pada anak adalah usia 24-36 bulan dan keterampilan ini tercapai pada fase batita [4]. Apabila toilet training dilakukan pada anak usia kurang dari 24 bulan akan berdampak pada durasi latihan yang lebih lama [5].

Anak yang dilakukan toilet training sebelum usia 24 bulan dan setelah 36 bulan lebih cenderung mengalami permasalahan seperti konstipasi [4]. Berdasarkan hasil penelitian sebelumnya, usia mempengaruhi keterampilan $\mathrm{BAB}$ dan BAK dalam hal pencapaian kesiapan toilet training. Pada penelitian ini responden telah dipilih dengan kriteria memenuhi syarat kesiapan toilet training, sehingga pada penelitian ini variabel usia tidak mempengaruhi peningkatan keterampilan buang air kecil dan buang air besar. Pemilihan responden yang telah memiliki kesiapan toilet training pada penelitian ini, merupakan penerapan konsep dengan pendekatan berfokus pada anak, dengan mengadaptasi panduan dari American Academy of Pediatric. Para ahli dengan pendekatan ini sepakat bahwa anak yang akan diberikan toilet training harus sudah memiliki kesiapan toilet training terdiri dari kesiapan fisik, kognitif, dan interpersonal [16].

Mengajarkan toilet training pada anak menggunakan potty membutuhkan 
kesabaran, pengertian dan waktu. Hal terpenting yang perlu diingat adalah bahwa orangtua tidak dapat memaksakan anak untuk menggunakan toilet. Orang tua harus memahami dan mengerti akan tanda-tanda kesiapan anak untuk memulai potty training yang meliputi anak mampu mengembangkan kontrol kandung kemih seperti anak menyadari popok basah atau kotor, anak mampu berkomunikasi menyatakan keinginan untuk BAB dan BAK [17].

Berdasarkan tabel 1, masih banyak anak yang menggunakan diapers walau hanya saat malam hari, pada kondisi tertentu dan sepanjang hari. Penggunaan diapers pada anak dalam rentang waktu yang lama akan mengakibatkan anak mengalami ketergantungan. Penggunaan diapers membuat anak akan terbiasa untuk melakukan buang air besar dan buang air kecil di popok, sehingga akan terbentuk menjadi kebiasaan dan menimbulkan rasa lebih nyaman pada anak, dan menimbulkan masalah dalam proses toilet training dan ketercapaian keterampilan buang air kecil dan buang air besar [18].

Pemberian potty training dilakukan 3 kali dalam seminggu dan selama 1 bulan dengan durasi 15-30 menit. Hal ini sejalan dengan penelitian yang dilakukan oleh Drysdale yang menyatakan bahwa minimal keterampilan buang air kecil dan buang air besar yang diperoleh dari pembelajaran dengan potty training dapat dipertahankan selama 4 minggu [19].

Tahapan pemberian potty training pada penelitian ini meliputi mengenali simbol atau kosa kata anak dalam menyampaikan keinginan untuk BAB dan BAK, menyebutkan tanda untuk BAB dan BAK, mengajarkan anak untuk melepaskan celana, duduk di kursi potty, lakukan BAB dan BAK, membersihkan kemaluan, menggunakan celana dan menyiram potty. Tahapan ini hampir sama dengan penelitian yang dilakukan oleh Drysdale dan McLay yang menyatakan bahwa mengajarkan keterampilan buang air besar dan buang air kecil pada anak secara berurutan terdiri dari mandiri berjalan ke toilet, melepaskan celana, duduk di toilet, buang air besar dan kecil di toilet, membersihkan kemaluan, mengenakan celana kembali dan menyiram toilet $[19,20]$.

Keterampilan BAB dan BAK pada anak yang dievaluasi meliputi keterampilan mengenal kosa kata dan tanda-tanda buang air kecil terdiri dari pertanyaan mengenai keterampilan anak untuk dapat menyampaikan keinginan menggunakan kata-kata atau secara lisan, serta menunjukkan ekspresi seperti menunjukkan gerakan-gerakan saat akan buang air kecil atau buang air besar. Keterampilan buang air kecil dan buang air besar terdiri dari pertanyaan mengenai kemandirian anak dalam melakukan tahapan-tahapan buang air kecil dan buang air besar. Aspek lain terdiri dari pertanyaan mengenai penggunaan diapers, melakukan buang air kecil dan air besar di toilet, serta mengompol di siang hari dan malam hari.

Evaluasi keterampilan BAB dan BAK pada penelitian ini dilakukan setelah 4 minggu anak diberikan potty training. Pada dasarnya, imitasi pada batita merupakan proses pembelajaran dengan retensi yang lama [21]. Studi terdahulu menyampaikan bahwa minimal keterampilan buang air kecil dan buang air besar yang diperoleh dari pembelajaran dengan mengunakan media seperti potty dapat dipertahankan selama 4 minggu [19].

Keberhasilan pemberian potty training dalam penelitian ini didukung oleh reinforcement. Reinforcement yang diberikan dalam penelitian ini berbentuk pujian. Reinforcement diberikan dengan menunjukkan 2 ibu jari dan menyampaikan bahwa anak pintar, cerdas, dan hebat. Reinforcement dapat diberikan oleh orangtua di rumah yang sebelumnya telah diberi penjelasan oleh peneliti tentang cara menyampaikan reinforcement. 
Reinforcement dalam penelitian ini digunakan untuk menguatkan dan mempertahankan perilaku anak tanpa memberikan penekanan dan pemaksaan pada anak. Responden yang berhasil mencapai keterampilan buang air kecil dan buang air besar mendapatkan reward berupa pujian, yang berdampak pada peningkatan kepercayaan diri dan upaya untuk mempertahankan keterampilan. Hal ini sejalan dengan penelitian yang dilakukan di Belgia yang menyatakan bahwa sebagian besar orangtua memberikan reward pada anak saat anak berhasil mencapai suatu keterampilan dengan tujuan agar anak terus mempertahankan keterampilan yang dicapai [22].

Keberhasilan pemberian potty training tergantung pada persiapan anak dan orang tua terutama ibu. Potty training memberikan keuntungan bagi anak antara lain anak dapat mengontrol dan melakukan sendiri buang air kecil dan buang air besar secara mandiri serta mulai belajar mengetahui beberapa bagian tubuh dan fungsinya.

\section{SIMPULAN}

Pemberian potty training selama Tiga kali dalam seminggu selama Empat minggu pada anak usia BATITA dapat meningkatkan keterampilan buang air besar dan buang air kecil pada anak. Hasil uji statistik menunjukkan bahwa ada pengaruh pemberian potty training terhadap keterampilan buang air besar dan buang air kecil pada anak usia BATITA.

\section{UCAPAN TERIMA KASIH}

Peneliti mengucapkan terima kasih kepada seluruh responden dan orang tua yang telah berpartisipasi dalam proses penelitian. Peneliti juga mengucapkan terima kasih kepada Direktorat Riset dan Pengabdian Masyarakat, Kementerian Riset, Teknologi dan Pendidikan Tinggi atas dukungan yang diberikan kepada penulis berupa bantuan dana penelitian.

\section{REFERENSI}

[1] Wong DL, Hockenberry MJ, Wilson D. Wong's nursing care of infants and children. Mosby/Elsevier,; 2015.

[2] Ranuh S. Tumbuh Kembang Anak Edisi 2. Buku Jakarta: Kedokteran EGC. 2014.

[3] Yang SS, Zhao LL, Chang SJ. Early initiation of toilet training for urine was associated with early urinary continence and does not appear to be associated with bladder dysfunction. Neurourology and urodynamics. 2011 Sep;30(7):1253-7. Available from: https://doi.org/10.1002/nau.20982

[4] Hodges SJ, Richards KA, Gorbachinsky I, Krane LS. The association of age of toilet training and dysfunctional voiding. Res Reports Urol. 2014;6:127-30. Available from: https://doi.org/10.2147/RRU.S66839

[5] Mota DM, Barros AJ, Matijasevich A, Santos IS. Longitudinal study of sphincter control in a cohort of Brazilian children. Jornal de pediatria. 2010;86:429-34. Available from: https://doi.org/10.1590/S002175572010000500013

[6] Liu X, Sun Z. Age of attaining nocturnal bladder control and adolescent suicidal behavior. J Affect Disord. 2005;87(2-3):281-9. Available from:

https://doi.org/10.1016/j.jad.2005.05.010

[7] Kyle, T. and Carman, S.,Buku ajar keperawatan pediatri. EGC. 2015

[8] Salih AA. Nocturnal enuresis: Prevalence and associated Factors. A sample of children in Baghdad. Middle East J Fam Med. 2012 Jun 1;10(5):29-32.

[9] Fockema MW, Candy GP, Kruger D, Haffejee M. Enuresis in South African children: prevalence, associated factors and parental perception of treatment. BJU international. 2012 Dec;110(11c):E1114-20. https://doi.org/10.1111/j.1464410X.2012.11416.X

[10] Kaerts N, Vermandel A, Van Hal G, Wyndaele JJ. Toilet training in healthy children: Results of a questionnaire study involving parents who make use of day-care at least once a week. Neurourology and urodynamics. 2014 Mar;33(3):316-23. https://doi.org/10.1002/nau.22392

[11] Cohen L, Manion L, Morrison K. Research Methods in Education. 5th Editio. Research Methods in Education. 2017. 
[12] Lee WD. Buku ajar keperawatan pediatrik Wong: Edisi 6. Jakarta: EGC. 2009.

[13] Carey WB, Crocker AC, Elias ER, Feldman HM, Coleman WL. Developmental-Behavioral Pediatrics E-Book. Elsevier Health Sciences; 2009 Apr 30.

[14] Purwandari H. Perkembangan Balita: Deteksi dan Stimulasi Tumbuh kembang Balita. Yogyakarta: Pustaka Pelajar. 2014.

[15] Soetjiningsih DS. Tumbuh kembang anak. Jakarta: EGC. 2013.

[16] Garzon DL, Starr NB, Brady MA, Gaylord NM, Driessnack M, Duderstadt K. Burns' Pediatric Primary Care E-Book. Elsevier Health Sciences; 2019 Nov 13.

[17] Noakes A. Potty training tips for parents. Journal of Health Visiting. 2018 Jul 2;6(7):328-. Available from: https://doi.org/10.12968/johv.2018.6.7.328

[18] Barone JG, Jasutkar N, Schneider D. Later toilet training is associated with urge incontinence in children. J Pediatr Urol [Internet]. 2009;5(6):458-61. Available from: http://dx.doi.org/10.1016/j.jpurol.2009.05.01 2

[19] Drysdale B, Lee CYQ, Anderson A, Moore DW. Using Video Modeling Incorporating Animation to Teach Toileting to Two Children with Autism Spectrum Disorder. J Dev Phys Disabil. 2015;27(2):149-65. https://doi.org/10.1007/s10882-014-9405-1

[20] McLay L, Carnett A, van der Meer L, Lang R. Using a Video Modeling-Based Intervention Package to Toilet Train Two Children with Autism. J Dev Phys Disabil. 2015;27(4):431-51. https://doi.org/10.1007/s10882-015-9426-4

[21] Hergenhahn, B.R. \& Olson, M.H. Theories of Learning. Jakarta: Kencana Prenadamedia Group. 2014.

[22] van Nunen K, Kaerts N, Wyndaele JJ, Vermandel A, van Hal G V. Parents' views on toilet training (TT): A quantitative study to identify the beliefs and attitudes of parents concerning TT. J Child Heal Care. 2015;19(2):265-74. https://doi.org/10.1177/1367493513508232 